\title{
Grensoverschrijdende schatvinding en het Pruisische landrecht
}

\author{
Pruisisch privaatrecht
}

Het Allgemeines Landrecht für die Preussischen Staaten dat in werking trad op 1 juni 1794 staat bekend als een van de uitvoerigste wetboeken uit de moderne tijd. Het bevatte maar liefst negentienduizendhonderdvierennegentig (zegge: 19.194) paragrafen en besloeg niet alleen het klassieke privaatrecht, maar ook het handelsrecht, grote delen van het publiekrecht, het kerkrecht, enzovoorts. Het ALR zit vol met voorschriften die een interessant inkijkje geven in de gebruiken van de tijd waarin het werd ontworpen, en die ook veel duidelijk maken over de invloed die de Pruisische vorst Frederik II als verlicht despoot wenste uit te oefenen op zijn onderdanen. ${ }^{1}$ Zo bevatte het wetboek bijvoorbeeld drie bepalingen over de echtelijke plicht. Die mochten echtelieden elkaar niet voortdurend 'anhaltend' weigeren (ALR II, I, §178). Wel kon het nakomen van de echtelijke plicht geweigerd worden, als het naleven ervan schade berokkende aan de gezondheid van één der echtelieden (II, I, §179). Vrouwen die borstvoeding gaven 'verweigern die Beywohnung mit Recht' (II, I §180). Aan het geven van borstvoeding waren nog enkele andere bepalingen gewijd. Een gezonde vrouw was verplicht dat zelf te doen (ALR II, II, §67). Dat zal een voor die tijd moderne bepaling zijn geweest: de vrouw mocht haar kind niet laten zogen door een min. ${ }^{2}$ De volgende bepaling was dan weer een stuk minder modern: de vader bepaalde hoe lang de vrouw borstvoeding gaf, zij het dat hij 'overruled' kon worden door een deskundige als de gezondheid van de moeder of die van het kind te lijden hadden van de vaderlijke wil.

De opstellers van het ALR streefden als gevolg van de grote natuurrechtelijke invloed op het wetboek ${ }^{3}$ materiële volledigheid na: het wetboek moest voor ieder denkbaar geval regels

1 C. Clark, Iron Kingdom, The Rise and downfall of Prussia 1600-1947, Londen 2007, p. 281: 'With its almost 20.000 paragraphs that seem to spy into the foundations of every conceivable transaction between one Prussian and another, the General Code was the greatest civilian achievement of the Frederician Enlightenment.' H. Coing (Europäisches Privatrecht II, München 1989, p. 10) noemde het ALR een 'Gesamtordnung des gesellschaftlichen Lebens.'

2 G. Dilcher, ('Die Janusköpfige Kodifikation', in: ZeuP 1994, p. 446-469, p. 464) sprak in verband met de 'gern zitierte' bepalingen over borstvoeding van de 'gesundheitspolitisch durchaus modernen Säugepflicht der Mutter'.

3 Vgl. bijvoorbeeld F. Wieacker, Privatrechtsgeschichte der Neuzeit, Göttingen 1952, p. 204: 'preußisches Naturrecht'. Een overzicht over het ALR (met literatuurverwijzingen) van de hand van P. Hellwege is te vinden in het online te raadplegen Handwörterbuch des Europäischen Privatrechts, lemma: 'Allgemeines Landrecht für die Preußischen Staaten'. Vgl. nog H. Hattenhauer (red.), Allgemeines Landrecht für die Preußischen Staaten von 1794, 3e druk 1996 (wettekst en literatuur). 
bevatten en zo de rol van de rechter als rechtsvormer minimaliseren. De rechter kreeg geen ruimte om bijvoorbeeld door middel van algemene bepalingen en open normen op de stoel van de wetgever te gaan zitten. ${ }^{4}$ Wanneer de wettekst onduidelijk was, mocht hij wel een oordeel vellen, maar moest hij de onduidelijkheid van de wet doorgeven aan een wetgevingscommissie die richting kon geven voor latere gevallen. ${ }^{5}$ Het is zo bezien opmerkelijk dat het wijdlopige ALR níet als een uitputtend wetboek was bedoeld, maar als doel had het in die tijd subsidiaire Romeinse recht, het ius commune, te vervangen als hulpbron van het privaatrecht. Dilcher karakteriseerde het ALR in een herdenkingsartikel uit 1994 als een wetboek met twee gezichten, net als de Romeinse godheid Janus bifrons. Het was gericht op verleden en toekomst. Het ALR weerspiegelde de overgangsfase tussen het regionale, van streek tot streek verschillende privaatrecht dat de erfenis was van de Middeleeuwen, en het geüniformeerde, genationaliseerde privaatrecht dat in de negentiende eeuw in Europa zijn intrede deed. ${ }^{6}$

Een groot succes is het ALR niet geweest. Bekend is de kritiek die de invloedrijke F.C. von Savigny (1779-1861) erop uitte. Het ALR maakte volgens hem duidelijk dat het in 1794 te vroeg was geweest om een wetboek te maken. ${ }^{7}$ In een brief aan zijn zwager noemde Savigny het wetboek 'in Form und Materie eine Sudeley' (naar vorm en inhoud een gedrocht). ${ }^{8}$ De uitvoerigheid van het ALR bemoeilijkte onderwijs erin en ook de verschijning van handboeken. ${ }^{9}$ Veel studenten hadden er bij het verlaten van de universiteit geen kennis van. ${ }^{10}$ De uitgebreidheid van het ALR moge het zwakke punt van dit wetboek zijn, het is tegelijkertijd zijn sterke punt: juist omdat de opstellers alles wilden regelen bevat het ALR voor de meest uiteenlopende gevallen bepalingen. Het kon daarbij putten uit de rijke

$4 \quad$ Zie bijvoorbeeld $\S 6$ van de Inleiding bij het ALR: Auf Meinungen der Rechtslehrer, oder ältere Aussprüche der Richter, soll, bey künftigen Entscheidungen, keine Rücksicht genommen werden.

5 Vgl. over deze afgezwakte variant van référé législatif, J.H.A. Lokin, 'Lex semper loquitur', in: GROM 1984, p. 1-50, over het ALR op p. 6-8. Zoals de meeste van dergelijke mechanismen werkte dit systeem niet, de wetgever trok het op 21 maart 1798 alweer in, vgl. W. Wagner, 'Die Wissenschaft des gemeinen römischen Rechts und das Allgemeine Landrecht für die Preussischen Staaten', in: H. Coing, W. Wilhelm (red.), Wissenschaft und Kodifikation des Privatrechts im 19. Jahrhundert, Bd I, Frankfurt 1974, p. 119-152, p. 147

6 G. Dilcher, 'Die janusköpfige Kodifikation', in: ZeuP 1994, p. 446-469, p. 465-467. Iets vergelijkbaars merkte Madame de Staël op over het verlicht-militaristische Pruisen. Het geldt ook voor het ALR zoals de moderne en paternalistische bepalingen over borstvoeding illustreren.

$7 \quad$ Vom Beruf unsrer Zeit für Gesetzgebung und Rechtswissenschaft, Heidelberg 1814, p. 81 e.v., p. 84.

8 Savigny's zwager velde een veel positiever oordeel over het wetboek. Hij stelde in zijn antwoord aan Savigny dat het ALR net zo belangrijk was als Luthers Bijbelvertaling, vgl. over de brieven D. KästleLamparter, Welt der Kommentare, Tübingen 2016, p. 63. Zie ook J.H.A. Lokin, 'Wetboek of landrecht', in: RMThemis 1994, p. 97-99.

9 Vgl. hierover W. Wagner, 'Die Wissenschaft des gemeinen römischen Rechts und das Allgemeine Landrecht für die Preussischen Staaten', in: H. Coing, W. Wilhelm (red.), Wissenschaft und Kodifikation des Privatrechts im 19. Jahrhundert, Bd I, Frankfurt 1974, p. 119-152, p. 140-145; P. Hellwege 'ALR', in: Handwörterbuch des Europäischen Privatrechts, nr 7. Zo verscheen bijvoorbeeld het commentaar van F.W. Bornemann vanaf 1834 en dat van C.F. Koch vanaf 1852. De systematischere leerboeken van F. Förster en H. Dernburg verschenen vanaf 1865 respectievelijk 1875.

10 P. Hellwege, 'ALR', in: Handwörterbuch des Europäischen Privatrechts, nr 7. 


\section{GRENSOVERSCHRIJDENDE SCHATVINDING EN HET PRUISISCHE LANDRECHT}

catalogus van zaken, literatuur en verhalen die zijn voorganger, het ius commune, had opgeleverd.

\section{Schatvinding in Pruisen}

De rijkdom aan casus in het ALR illustreer ik aan de hand van de regeling van schatvinding. Het ALR telde maar liefst tweeëndertig artikelen (I, IX, §74-106) over deze wijze van eigendomsverkrijging. De Romeinse regeling van schatvinding is in het ALR gemakkelijk te herkennen. Zo verwierf de ontdekker van een schat volgens het ALR het ontdekkersaandeel als hij op andermans grond groef, alleen wanneer het ging om een toevallige vondst ( $\$ 82$ e.v.) Dat was in het Romeinse recht ook zo (CJ. 10,15,2). Het ALR ontzegde verder -net als het Romeinse recht- de vinder enig aandeel in een schat als hij die gevonden had na gebruik te hebben gemaakt van tovermiddelen, het aanroepen van doden, of andere vormen van bijgeloof ('Aberglauben') en zwendel ('Gaukely'). De Staat verwierf zijn aandeel (I, IX, $\S 86$ en 88, voor het Romeinse recht CJ. 10,15,1,1). ${ }^{11}$ Het ALR bevatte daarnaast nog allerlei bepalingen over kwesties van schatvinding waarover in het ius commune vragen waren gerezen. Konden bijvoorbeeld de vruchtgebruiker, de erfpachter en de opstaller aanspraak maken op het eigenaarsaandeel van een schat, gevonden in de grond of het gebouw, dat zij gebruikten? Het ALR ontzegde de vruchtgebruiker en de erfpachter aanspraak op het eigenaarsaandeel. De opstaller verwierf dat aandeel wanneer de schat gevonden werd in het gebouw waarvan hij eigenaar was. ${ }^{12}$ Wat te doen wanneer een schat werd gevonden in verkochte, nog niet geleverde grond? Volgens de meeste gemeenrechtelijke auteurs, zoals Voet en Glück, was het eigenaarsaandeel voor de verkoper, maar had de koper uit de overeenkomst aanspraak op overdracht als hij ten tijde van de vondst het risico droeg dat de zaak door overmacht tenietging. ${ }^{13}$ Het ALR koos een iets andere oplossing: het eigenaarsaandeel was voor de verkoper tenzij op de koper ten tijde van de ontdekking het risico rustte dat de zaak door overmacht tenietging (I, IX, §99 en $\S 100)$ : dan kreeg de koper het 'eigenaars'aandeel. ${ }^{14}$ Het ALR bevatte ook nog een bepaling

11 Vgl. hierover ook J.H.A. Lokin, 'Wetboek of landrecht', in: RMThemis 1994, p. 97-99.

12 Vgl. daarover bijvoorbeeld J. Voet, Commentarius ad Pandectas, II, Den Haag 1726, D. 41,1 nr 12 (p. 726-727): de erfpachter en de leenman kregen het eigenaarsaandeel, de vruchtgebruiker niet, een zekerheidsrecht op de grond omvatte niet de daar gevonden schat. Vgl. voor het Nederlandse recht de artikelen 5:101 BW (opstaller als eigenaar van de opstal), 5:93 (de erfpachter verwerft het eigenaarsaandeel) en 3:213 lid 2 (het vruchtgebruik op de zaak waarin de schat zich bevindt, strekt zich uit over de schat).

13 J. Voet, Commentarius ad Pandectas, II, Den Haag 1726, ad D. 41,1, nr. 12 (p. 727) en C.F. Glück, Ausführliche Erläuterung der Pandecten nach Hellfeld, Bd 17,1, Erlangen 1815, p. 190 e.v.

14 F. Förster, Preußisches Privatrecht, Bd 3, Berlijn 1892, p. 217. Het BGB keerde terug naar de gemeenrechtelijke leer, vgl. R. Knütel, 'Von Landanschwemmungen und Schätzen. Die commoda ex re vendita und $\S 446$ BGB', in: G. Baumgärtel e.a. (red.), Festschrift für Heinz Hübner, Berlijn-New York 1984, p. 551-573, p. 568-569, over het ALR op p. 566. Vgl. ook J.E. Jansen, 'Periculum est emptoris: over risico en koop en schatvinding in de gekochte zaak', in: AAe 2020, p. 454-462 die de gemeenrechtelijke leer voor het Nederlandse recht verdedigt. 
over de verwerving van het eigenaarsaandeel voor gevallen waarin iemand wist dat zich ergens een schat bevond, bijvoorbeeld als gevolg van een archiefvondst, om de grond vervolgens te kopen -zonder zijn kennis met de verkoper te delen- en dan de schat snel op te graven. De koper verwierf volgens het ALR niet meer dan het vindersaandeel (I, IX, $\S 101)$. De Pruisische literatuur toonde zich weinig enthousiast over deze oplossing. Gruchot schreef:

'Es beruht daher die Vorschrift (...) auf einer ganz ungehörigen Anwendung des im Allgemeinen Landrechte überall verwaltenden moralischen Princips. ${ }^{15}$

Het voorschrift moraliseerde in de woorden van Förster tot schade van de juridische gevolgtrekking. ${ }^{16}$ De Bijbelvaste lezer zal deze kwestie in verband hebben gebracht met een passage uit het evangelie van Mattheus $(13,44)$ :

Wederom is het Koninkrijk der hemelen gelijk aan een schat, in de akker verborgen, die een mens gevonden hebbende, verborg die, en van blijdschap erover, gaat hij heen en verkoopt al wat hij heeft, en koopt die akker.

De vraag of degene die wist dat zich ergens een schat bevond dat aan de verkoper moest melden, had de gemeenrechtelijke juristen beziggehouden. ${ }^{17}$ Pufendorf (1632-1694) was van mening dat het de koper was toegestaan winstgevende voorkennis over het koopobject voor zich te houden. Hij verwees hierbij naar de hierboven geciteerde Bijbelpassage, en noemde nog het voorbeeld dat iemand wist dat er ergens edelstenen te vinden waren. Er gold voor dit soort kennis geen informatieplicht. ${ }^{18}$ Alciatus (1492-1550) wilde op het geval van de door de koper niet met de verkoper gedeelde voorkennis omtrent de aanwezigheid van een schat het leerstuk toepassen van de laesio enormis (buitengewone benadeling). Dat leerstuk gaf de verkoper die voor minder dan de helft van de waarde een zaak had verkocht de mogelijkheid om, te zijner keus, de verkochte zaak terug te vragen tegen afgifte van de ontvangen prijs, of aanvulling te vragen van de koopprijs tot de helft. ${ }^{19}$ Alciatus schreef het volgende:

'Als ik wetende dat zich daar een schat bevindt, gekocht heb van jou die het niet wist, en de grond vanwege de schat meer waard is dan de helft van wat ik heb betaald, volgt uit de billijkheid dat de verkoper uit de wet een rechtsvordering wordt toegestaan, waarmee ofwel de overeenkomst wordt

15 J.A. Gruchot, 'Glossen zum Allgemeinen Landrecht (III) ', in: Beiträge zur Erläuterung des preußischen Rechts durch Theorie und Praxis, 1862 (Bd 6), p. 567-624, p. 593.

16 F. Förster, Preußisches Privatrecht, Bd 3, Berlijn 1892, p. 217.

17 Vgl. met verwijzingen naast de in de hoofdtekst besproken auteurs R. Knütel, 'Der Schatz im Acker', Juristische Schulung 1986, p. 950-957, i.h.b. op p. 951-954.

18 S. von Pufendorf, De jure naturae et gentium VIII, Frankfurt 1684, V.3.3., p. 701.

19 Vgl. bijvoorbeeld CJ. 4,44,2 daarover J.H.A. Lokin/F. Brandsma, Prota, Vermogensrechtelijke leerstukken aan de hand van Romeinsrechtelijke teksten, Den Haag 2016, V49 (p. 284); R. Zimmermann, The law of obligations. Roman foundations of the civilian tradition, Oxford 1996, p. 259 e.v. 


\section{GRENSOVERSCHRIJDENDE SCHATVINDING EN HET PRUISISCHE LANDRECHT}

ontbonden of dat aan hem de rechtvaardige prijs wordt gegeven. ${ }^{20}$

Hij ging er dus vanuit dat de koopovereenkomst niet alleen als voorwerp had de grond en de zich daar bevindende opstallen, maar ook de schat in de grond. Dat lijkt een wat gekunstelde aanname, de schat moet dan immers als bestanddeel gelden van de grond -in strijd met D. 41,2,3,3- om er maar voor te zorgen dat de verkoper zich op laesio enormis kan beroepen. ${ }^{21}$

\section{Antiek juridisch tourisme: grensoverschrijdende schatvinding}

Het ALR kende tot slot drie artikelen over de vondst van een schat op de grens van twee of meer erven. De eigenaren van de erven deelden in zo'n geval het eigenaarsaandeel in de schat. Het deed er daarbij volgens het ALR niet toe dat de schat voor het grootste gedeelte in het ene erf lag, en maar voor een klein stukje in het andere (I, IX, §91 en §92). Deze drie artikelen over de vondst van een schat op de grens tussen twee erven gaan terug op het werk van Augustin (von) Leyser (1683-1752). ${ }^{22}$ Hij studeerde rechten in Wittenberg en Halle en maakte zoals wel meer studenten in die tijd een academische rondreis door Europa. Hij deed

20 A. Alciatus, Opera Omnia IV, Frankfurt 1617, Parergon, VII caput I, op. p. 393: si ego sciens esse ibi thesaurum, a te ne sciente emerim, fundusque propter thesaurum supra dimidium eius pretii, quod impendi, valeret: suadet aequitas ut venditori condictio ex lege concedatur, qua vel rescindatur contractus, vel restituatur iustum pretium.

21 R. Knütel, 'Der Schatz im Acker', in: Juristische Schulung 1986, p. 950-957, op p. 951. Harpprecht wijst daar in zijn Institutencommentaar ook op, en wil de verkoper daarom een uit de billijkheid voorvloeiende analoge actie toekennen. Zo is het net alsof de koper de schat gevonden had toen de schat zich nog in de grond van de verkoper bevond: had de koper niet van de schat geweten, dan had hij de grond niet gekocht, had de verkoper er wel van geweten dan had hij de grond niet verkocht, J. Harpprecht, Commentarius in quator libros Institutionum, $4^{\mathrm{e}}$ editie deel II, Lausanne 1748, 2,1 §39, nrs 13 en 14 (p. 375). Nog weer een andere oplossing om de verkoper tegemoet te komen, zou erin bestaan aan te nemen dat de koper de schat ontdekte, niet toen hij hem opgroef, maar toen hij de archiefvondst deed. Toen was de grond immers nog van de verkoper, aan wie dan dus het eigenaarsaandeel toekomt. De Boer sprak zich -in een iets andere context- uit voor zo'n minder feitelijk ontdekkersbegrip, zie J. de Boer, 'De schatvinding in het Nieuwe Burgerlijk Wetboek en in de Monumentenwet, mede gezien in het licht van haar geschiedenis', in: RMThemis 1973, p. 421-465, p. 425. Meijers wilde er niet van weten: opgraven is vereist, TM bij art. 5.2.9., Parl. Gesch. Boek 5, p. 102. De Erfgoedwet heeft deze kwestie van veel belang beroofd. Degene namelijk die naar aanleiding van een archiefvondst naar een schat graaft en er één vindt, doet een opgravingsvondst. Van zo'n vondst verwerft de Staat op grond van de Erfgoedwet de eigendom, zonder dat hij verplicht is de bij de vondst betrokkenen te compenseren. Het doet er daarom niet veel toe of een archiefvondst als ontdekking kan gelden en ook niet of de koper verplicht is zijn voorkennis te delen, vgl. daarbij HR 19 juni 1959, NJ 1960/59 (Kantharos van Stevensweert).

22 Vgl. over Leyser K. Luig, 'Leyser, Augustin Freiherr von', in: Neue Deutsche Biographie 14 (1985), p. 437-439. De verwijzing naar Leyser bij dit deel van het ALR bijvoorbeeld bij F. Förster, Theorie und Praxis des heutigen gemeinen preussischen Privatrechts auf der Grundlage des gemeinen deutschen Rechts, Bd 3, Berlijn 1874, p. 187; F.W.L. Bornemann, Systematische Darstellung des Preußischen Civilrechts mit Benutzung der Materialien des Allgemeinen Landrechts, $2^{\mathrm{e}}$ druk Bd 2, Berlijn 1842, p. 21 in noot 3. 
Holland aan, Engeland en natuurlijk Italië. Hij was hoogleraar in Helmstedt en Wittenberg en werkte ook lange tijd als rechter in verschillende gerechtshoven. Hij arbitreerde en adviseerde en zat vele disputaties voor. Leyser bundelde zijn ruime en veelzijdige ervaringen in een elfdelig werk waarin hij de zaken plaatste en besprak in de volgorde van de Digesten. Deze Meditationes ad Pandectas (Overdenkingen bij de Pandekten) verschenen tussen 1713 en 1748. In het zevende deel besteedde Leyser aandacht aan de Romeinsrechtelijke schatvindingsregels.

Hij besprak er een rechtszaak die de Franse monnik Bernard de Montfaucon (1655-1741) noemde in zijn verslag van de reis die hij maakte vanuit Frankrijk naar Italië, zijn in het Latijn geschreven Diarium Italicum. ${ }^{23}$ Er was onder een kelder in een woonhuis in de Via Leutari een beeld gevonden. Het was een groot marmeren beeld van zo'n drie meter dat zich over twee erven uitstrekte: de scheidsmuur stond op de hals. Het beeld stelde de republikeinse generaal Pompeius voor. De twee buren bestreden elkaar de eigendom van dit grensgeval: de vinder stelde eigenaar te zijn omdat het grootste gedeelte van het beeld onder zijn erf lag. De buurman stelde dat het beeld van hem was omdat het nobeler deel (nobilior portio), het hoofd, zich onder zijn erf bevond. Het was bovendien de kop die duidelijk maakte dat het beeld Pompeius voorstelde. De onervaren rechter (iudex imperitus) oordeelde dat partijen het beeld maar moesten onthoofden, zodat ieder het deel kreeg dat in zijn grond lag. Toen Kardinaal Capodiferro (1501-1559) van deze stomme beslissing hoorde, stelde hij de onthoofding uit en waarschuwde de Paus, Julius III. ${ }^{24}$ Die liet het beeld bij zich brengen, betaalde de strijdende buren er 500 scudi voor die ze maar moesten delen, en schonk het beeld aan de kardinaal. Een beslissing passend bij de pauselijke waardigheid en toepasselijk voor een IJzerhoofd (Capo di Ferro betekent hoofd van ijzer), die het plaatste in zijn stadspaleis bij de Ponte Sisto.

Montfaucon tekende dit relaas op uit het werkje Roma ricercata van Martinelli (1599-1667), een in de tweede helft van de zeventiende eeuw populaire reisgids, waarin Martinelli -in het Italiaans- tien dagtochten uitzette voor buitenlandse touristen, met als uitvalsbasis de Via dell'Orso (waar goedkope hotels waren). ${ }^{25}$ Martinelli ontleende het verhaal op zijn beurt aan de beeldhouwer Flaminio Vacca (1538-1605) die het noemde in zijn in 1594 opgeschreven archeologische stadsherinneringen. ${ }^{26}$ Montfaucon voegde aan zijn bronnen toe dat het beeld nog op dezelfde plaats stond, in het stadspaleis dat naar een latere eigenaar bekend was komen te staan als het Palazzo Spada. Tegenwoordig zetelt daar de Italiaanse Raad van State. De meeste moderne toeristen zullen het gebouw kennen van een door

23 B. de Montfaucon, Diarium Italicum, Parijs 1702, p. 254.

24 Julius III (1487-1555), een kerkjurist, was Paus van 1550 tot zijn dood. Zie over zijn door (seks)schandalen overschaduwde pontificaat, J.J. Norwich, The Popes, Londen 2011, p. 304-305.

25 De eerste druk verscheen in 1644, ik gebruikte de 5e druk, F. Martinelli, Roma Ricercata, 1671, p. 34 (dagtocht III). Vgl. over deze zeventiende-eeuwse reisgids S. Fogelberg Rota, 'Fioravante Martinelli's Roma ricercata nel suo sito, and his "lettore forastiero" ', in: A. Blennow, S. Fogelberg Rota (edd.), Rome and the Guide Book Tradition: From the Middle Ages to the Twentieth Century, Berlijn-Boston 2019, p. 163-196.

26 F. Vacca, Memorie Di Varie Antichita Trovate In Diversi Luoghi Della Citta' Di Roma, zonder plaats en zonder jaartal, p. 11-12. 


\section{GRENSOVERSCHRIJDENDE SCHATVINDING EN HET PRUISISCHE LANDRECHT}

Borromini ingenieus ontworpen zinsbegoochelende portico. $\mathrm{Er}$ is ook een schilderijenmuseum gevestigd. Het reusachtige beeld is er te bezichtigen, voor degene die de moeite neemt tevoren een afspraak te maken, in de zaal van Pompeius ('salone di Pompeo').

\section{Pompeius en Caesar}

De lotgevallen van het beeld van Pompeius zullen tot de verbeelding hebben gesproken omdat zij enkele van de beroemdste verhalen uit de nadagen van de Romeinse republiek in herinnering brachten. Gnaeus Pompeius Magnus (106-48 voor Christus) ${ }^{27}$ was één van de machtigste Romeinen van zijn tijd. Hij mocht als succesvol legeraanvoerder tweemaal een triomftocht houden, bestierde later als drieman samen met Caesar de republiek, maar delfde het onderspit in de burgeroorlog tegen diezelfde Caesar. Hij vluchtte na de nederlaag in de slag bij Pharsalus naar Egypte. Bij zijn aankomst daar liet Ptolemaeus XIII hem op het strand onthoofden, niet van zins om steun te verlenen aan de verliezende partij in de burgeroorlog van een bevriende natie. Enkele dagen later kwam ook Caesar aan in Egypte. Die liet volgens Plutarchus een traan toen men hem het afgehakte hoofd en de zegelring liet zien van zijn voormalige schoonzoon (Pompeius was getrouwd geweest met Caesars dochter Julia). ${ }^{28}$ De interventie van de kardinaal en de Paus had Pompeius dus een tweede onthoofding bespaard:

'Was het niet genoeg dat het hoofd van Pompeius zelf was afgehakt door Ptolemaeus, dat hetzelfde gevaar zijn marmeren standbeeld bedreigde?'29

Het verhaal van de onthoofding van Pompeius door Ptolemaeus en de verovering van Egypte (en Cleopatra) door zijn tegenstrever Caesar heeft iets ironisch omdat Caesar nog geen vier jaar na Pompeius' gewelddadige dood een vergelijkbaar lot trof. Hij werd vermoord door een groep senatoren op de Iden van Maart van het jaar 44 voor Christus, tijdens een vergadering in de curia van het door Pompeius gebouwde theater. De dictator stierf er aan de voet van een standbeeld van zijn oude tegenstrever dat daar stond. De gedachte dat het uitgerekend dit standbeeld was, dat in de Via Leutari was teruggevonden onder de kelders, was te aantrekkelijk om niet waar te zijn. Daar waren ook wel aanwijzingen voor. Zo liet keizer Augustus (Caesars achterneef en per testament ook diens geadopteerde zoon) het standbeeld van Pompeius op een marmeren boog plaatsen tegenover

27 Over hem bijvoorbeeld R. Seager, Pompey the Great, Oxford 2002.

28 Plutarchus, Parallelle levens, 80,5.

29 Miserum Pompeium! Annon satis erat caput ipsi a Ptolemæo amputatum, ut etiam iam marmorea statua in simile periculum veniret?, B. de Montfaucon, Diarium Italicum, Parijs 1702, p. 254. 
de galerij van het theater van Pompeius. ${ }^{30}$ Dat kwam redelijk overeen met de vindplaats van het beeld in de Via Leutari. Bovendien zaten er op de onderkant van het beeld rode spatten: dat zou het bloed van Caesar zijn. Het verhaal van de Spada-Pompeius raakte via Gibbon, die er in zijn Decline and Fall aandacht aan besteedde ${ }^{31}$, ook in Engelse kringen bekend. Byron (1788-1824) wijdde er in Childe Harold's Pilgrimage de volgende regels aan:

\author{
'And thou dread statue! Yet existent in \\ The austerest form of naked majesty \\ Thou who beheldest' mid the assassins din, \\ At thy bathed base the bloody Caesar lie, \\ Folding his robe in dying dignity \\ And offering to thine altar from the queen \\ Of Gods and men, great Nemesis! Did he die \\ And thou too perish, Pompey? Have ye been \\ Victors of countless kings, or puppets of a scene?'
}

Tegenwoordig gelooft (bijna) niemand meer dat het standbeeld in het Palazzo Spada dat van Pompeius is, waar Caesar de dood vond. Uit onderzoek aan het beeld bleek dat de rode spatten geen bloed waren, maar sporen van gecorrodeerd metaal die wel vaker voorkomen op beelden uit de Oudheid. Verder bleek het marmer te dateren van geruime tijd na de dood van Pompeius en die van Caesar. Dat het beeld niet de republikeinse generaal Pompeius voorstelde, bleek ook uit verschillende attributen zoals een soort rijksappel die hij in zijn hand had: dat was een symbool voor de keizerlijke macht. Archeologen nemen nu overwegend aan dat het standbeeld de 'slechte' keizer Domitianus voorstelt en spreken van de zogezegde Pompeius. ${ }^{32}$

\title{
Schatvinding op de erfgrens
}

Keren wij na dit uitvoerige (kunst)historische intermezzo terug naar de Meditationes van Leyser. Hij achtte het oordeel van de rechter om het beeld te onthoofden onjuist omdat het ging om een ondeelbare zaak. Dan golden volgens Leyser de regels die keizer Justinianus

30 Suetonius, Keizers van Rome, Augustus 31,5. Waarom gaf Augustus de tegenstander van zijn adoptiefvader een prominente plek? Hij deed dat om zo de Republiek te verheerlijken die hij beweerde te hebben hersteld, zie A. Everitt, Augustus, 2007 z.p., p. 236-237.

31 E. Gibbon, The history of the decline and fall of the Roman Empire, XII Leipzig 1829, p. 361.

32 Zie bijvoorbeeld T. Moore, The works of Lord Byron, with his letters and journals and his life, VIII Londen 1833, op. p. 311-312, concluderend: 'At all events so imposing is the stern majesty of the statue, and so memorable is the story, that the play of the imagination leaves no room for the exercise of the judgment, and the fiction, if a fiction it is, operates on the spectator with an effect not less powerful than truth.' 


\section{GRENSOVERSCHRIJDENDE SCHATVINDING EN HET PRUISISCHE LANDRECHT}

had neergelegd in een constitutie over de schenking van een zaak aan verschillende eigenaren, CJ 8,54,34,2. Om te voorkomen dat de begiftigden tegen hun wil mede-eigenaren bleven, gaf de keizer in het principium van deze tekst degene die het grootste aandeel in de eigendom had gekregen de keuze de mede-eigenaar af te kopen en de gehele zaak te houden. Als de eigenaar van het grootste deel dat niet wilde, diende de zaak verdeeld te worden als dat zonder gevaar mogelijk was (CJ 8,54,32,2a). Was deling niet mogelijk zonder gevaar en wilde degene met het grootste aandeel de mede-eigenaar niet uitkopen, dan had de eigenaar van het minderheidsaandeel het recht de grootaandeelhouder uit te kopen (CJ 8,54,34,2b). ${ }^{33}$ Leyser kende de grondeigenaren bij schatvinding op de erfgrens dus een aandeel in het eigenaarsaandeel toe naar verhouding van het deel van de schat dat zich in hun erf bevond. De vinder had dus, omdat het grootste deel van het beeld nu eenmaal in zijn erf lag, het recht de buurman uit te kopen en het beeld te houden.

Het ALR bereikte een net iets ander resultaat door de grondeigenaren telkens gelijkelijk te laten delen in het eigenaarsaandeel, ongeacht hoe groot het deel was dat op het ene erf lag, en hoe groot het deel was dat op het andere erf lag. In het ontwerp voor een Duits wetboek had Johow dezelfde regel opgenomen (in $\S 3$ van artikel 174 van zijn Ontwerp). De bepaling werd later in het wetgevingsproces geschrapt omdat de regel te casuïstisch was, en bovendien innerlijk niet gerechtvaardigd leek. ${ }^{34}$ De opstellers van het BGB zullen daarbij hebben gedacht aan gevallen waarbij het wel vast te stellen was in welk erf zich welk deel van de schat bevond, gevallen zoals dat van de Spada-Pompeius.

De verwijdering van de aan het ALR ontleende paragraaf uit het ontwerp Johow kon, natuurlijk, niet verhinderen dat de Duitse literatuur aandacht besteedt aan de belangrijke kwestie van schatvinding op de erfgrens. De Duitse schrijvers volgen de door Leyser uitgestippelde route: de eigenaren van de erven waarin de schat zich bevond verwerven het eigenaarsaandeel naar rato van dat deel dat op hun erf lag. ${ }^{35}$ Daarmee is de regel van het ALR niet helemaal in de juridische vergetelheid geraakt: telkens wanneer niet duidelijk is hoe de verhoudingen tussen deelgenoten precies liggen, geldt op grond van $§ 742$ BGB de regel dat de aandelen gelijk zijn. Omdat bij schatvinding op de erfgrens vaak niet of erg lastig bewezen zal kunnen worden voor welk gedeelte de schat zich in het ene erf bevond, en voor welk gedeelte in het andere, zal de rechter vaak terugvallen op dat uitgangspunt van het ALR. ${ }^{36}$ Dat lijkt me naar Nederlands recht niet anders: artikel 5:13 kent de eigendom van een schat toe aan degene in wiens zaak hij wordt aangetroffen: dat zijn bij schatvinding

33 A. Leyser, Meditationes ad Pandectas VII, Leipzig 1736, in nr 442 onder III, p. 46-47.

34 H.H. Jakobs, W. Schubert (edd.), Die Beratung des Bürgerlichen Gesetzbuchs Sachenrecht I $\$ \S 854-$ 1017, Berlijn-New York 1985, p. 758: 'zu kasuistisch' en: 'innerlich gerechtfertigt nicht anerkannt.'

35 J. Oechsler, MüKo zum BGB, 8e druk 2020, §984 Rn 11, H.J. Wieling, Sachenrecht, 2e druk 2006, p. 526.

36 K.H. Gursky, W. Wiegand, Staudingers Kommentar zum BGB, Berlijn 2017, §984 Rn 12. Vgl. M. Schermaier, Beck online GrossKommentar zum BGB 2020, §984, Rn 28. 
op de erfgrens de beide erven. Daarbij zal doorslaggevend zijn voor welk deel de schat in het ene erf lag, en voor welk deel in het andere. De grondeigenaars delen dan naar rato in het eigenaarsaandeel. Omdat het, behoudens gevallen zoals die van het beeld van Pompeius, veelal niet vast te stellen zal zijn in welk erf de schat voor welk gedeelte precies lag, zal de oplossing van het ALR vaak de meest praktische zijn.

\section{Tot slot}

Het bovenstaande benadrukt wat een wonderlijk wetboek het ALR was. Enerzijds wilden de opstellers ervan een zo groot mogelijke invloed op het recht. Zij wilden de invloed van de rechter minimaliseren door voor alle denkbare gevallen gemakkelijk toepasbare regels te geven. De rechter moest zich bij de uitleg van die regels aan voorschriften omtrent wetsuitleg houden, en hij moest in het onwaarschijnlijke geval dat de wettekst niet duidelijk was de wetgevingscommissie waarschuwen. Anderzijds liet het ALR het van streek tot streek, van stad tot stad geldende primaire recht onaangetast. Het was immers slechts bedoeld om het subsidiaire ius commune te vervangen. Het kon daarbij putten uit een rijke door de eeuwen heen opgebouwde verzameling van beslissingen, opvattingen en verhalen, zoals dat van de verzwegen voorkennis omtrent een schat bij de koop van land, en dat van de grensoverschrijdende schatvinding. Het ALR legde tal van dit soort gevallen vast. Het biedt zo inspiratie voor moderne rechters die werken met een minder gedetailleerd wetboek met meer open normen, dat in de kern evenwel teruggaat op datzelfde ius commune dat het ALR verving en vastlegde. ${ }^{37}$ Het ALR functioneert als verbindingsschakel, als trait d'union tussen het moderne in wetten vastgelegde nationale privaatrecht, en het flexibelere Europese ius commune.

J.E. Jansen ${ }^{38}$

GRONINGEN

37 Vgl. in vergelijkbare zin K. Luig, 'Das Privatrecht im 'Allgemeinen Landrecht für die preußischen Staaten' von 1794', in: Archiv für die civilistische Praxis (1994), p. 521-541, die erop wees (p. 541) dat de rechtspraak en de literatuur veel regels uit het ALR inmiddels afleiden uit de tekst van het BGB. Hij schreef: '(...) daß das ALR ein trotz seiner Fehler gelungener erster Versuch einer Kodifikation des Privatrechts in einem deutschen Territorium war. Es war dick und kasuistisch, weil es genaue Anweisungen geben wollte. Es war janusköpfig, weil es nicht alle Brücken hinter sich abreißen wollte. Es bevormundete die Bürger, weil es die Gefahr von Streitigkeiten realistisch einschätzte und 'Wohlwollen' bewirken wollte.'

38 Jelle Jansen is als hoogleraar ius commune verbonden aan de vakgroep Rechtsgeschiedenis van de Rijksuniversiteit Groningen. 